\title{
Disulfiram/copper selectively eradicates AML leukemia stem cells in vitro and in vivo by simultaneous induction of ROS-JNK and inhibition of NF-KB and Nrf2
}

\author{
Bing $\mathrm{Xu}^{\star, 1,2,4}$, Shiyun Wang ${ }^{2,4}$, Rongwei $\mathrm{Li}^{2,4}$, Kai Chen², Lingli He${ }^{2}$, Manman Deng ${ }^{1}$, Vinodh Kannappan ${ }^{3}$, Jie Zha ${ }^{1}$, Huijuan Dong ${ }^{2}$ and
} Weiguang Wang ${ }^{3}$

Acute myeloid leukemia (AML) is a heterogeneous malignancy. Despite the advances in past decades, the clinical outcomes of AML patients remain poor. Leukemia stem cells (LSCs) is the major cause of the recurrence of AML even after aggressive treatment making, promoting development of LSC-targeted agents is an urgent clinical need. Although the antitumor activity of disulfiram (DS), an approved anti-alcoholism drug, has been demonstrated in multiple types of tumors including hematological malignancies such as AML, it remains unknown whether this agent would also be able to target cancer stem cells like LSCs. Here, we report the in vitro and in vivo activity of DS in combination with copper $(\mathrm{Cu})$ against $\mathrm{CD} 34^{+} / \mathrm{CD} 38^{+}$leukemia stem-like cells sorted from $\mathrm{KG} 1 \alpha$ and Kasumi-1 AML cell lines, as well as primary CD34 $4^{+}$AML samples. DS plus $\mathrm{Cu}(\mathrm{DS} / \mathrm{Cu})$ displayed marked inhibition of proliferation, induction of apoptosis, and suppression of colony formation in cultured AML cells while sparing the normal counterparts. DS/Cu also significantly inhibited the growth of human CD $34^{+} / C D 38^{+}$leukemic cell-derived xenografts in NOD/SCID mice. Mechanistically, DS/Cu-induced cytotoxicity was closely associated with activation of the stress-related ROS-JNK pathway as well as simultaneous inactivation of the pro-survival Nrf2 and nuclear factor- $k B$ pathways. In summary, our findings indicate that DS/Cu selectively targets leukemia stem-like cells both in vitro and in vivo, thus suggesting a promising LSC-targeted activity of this repurposed agent for treatment of relapsed and refractory AML.

Cell Death and Disease (2017) 8, e2797; doi:10.1038/cddis.2017.176; published online 18 May 2017

It is widely accepted that acute myeloid leukemia (AML), a clinically and biologically clonal disorder of hematopoietic progenitor cells, is initiated from a small subset of leukemia stem cells (LSCs). ${ }^{1,2}$ LSCs are relatively quiescent and thus highly resistant to chemotherapy and radiotherapy, therefore primarily contributing to the dismal clinical outcome for AML. ${ }^{3,4}$ Despite the conventional multi-drug combinational therapies, the most preferred and efficacious treatment, have largely improved the long-term disease-free survival (DFS) of patients with AML, virtually all of these patients will however eventually relapse owing to drug-resistant LSCs that are not eradicated by current standard therapies. Thus, this has become a major hindrance to success of AML treatment. ${ }^{5}$ To prolong the duration of DFS as well as overall survival, new therapeutic agents targeting LSCs with low/non systemic toxicity are urgently needed for AML treatment.

LSCs are well accepted to be a CD34-positive and CD38-negative cell population with the ability to reconstitute human $\mathrm{AML}$ in immunodeficient mice regardless of the morphological subtype of AML, ${ }^{6}$ although recent studies have suggested that LSCs could also exist in $\mathrm{CD} 34^{+} / \mathrm{CD} 38^{+}$or CD34- blast populations at least in some types of AML. ${ }^{7} \mathrm{KG} 1 \mathrm{a}$ and Kasumi-1 cell lines derived from male AML patients, both of which have high percentage of $\mathrm{CD} 34^{+} \mathrm{CD} 38^{-}$population, are widely used for in vitro and in vivo studies of LSCs. ${ }^{8}$
Disulfiram (DS) is a Food and Drug Administration (FDA)-approved anti-alcoholism drug that has been used in clinic for $>60$ years. $^{9,10}$ As a divalent metal ion chelator, DS is able to strongly chelate copper $(\mathrm{Cu})$ to form a disulfiram/ copper (DS/Cu) complex that has been reported to be highly active against various types of tumors, including melanoma, ${ }^{11-13}$ breast cancer, ${ }^{14-16}$ colon cancer, ${ }^{17}$ prostate cancer, ${ }^{18}$ as well as hematological malignancies including myeloid leukemia, ${ }^{19,20}$ but display low toxicity. However, it remains unknown whether DS/Cu would also be capable to target cancer stem cells such as LSCs.

Reactive oxygen species (ROS), the product of mitochondria oxidative phosphorylation, has a crucial role as an intracellular messenger in numerous biological events, including cell proliferation and survival. It is a consensus that excessive production of ROS results in peroxidation of lipid, protein, and DNA, leading to cellular damage and apoptosis. ${ }^{21}$ As tumor cells usually have to deal with higher levels of ROS than their normal counterparts, further increase of ROS by ROS-inducing agents, such as DS/Cu, could exhaust the cellular antioxidants, therefore resulting in apoptosis of tumor cells. ${ }^{19,22} \mathrm{C}$-jun $\mathrm{NH}_{2}$-terminal kinase (JNK), an important member of the MAPK family, has a crucial role in a variety of stress-triggered responses, including differentiation and apoptosis. ${ }^{23,24}$ Furthermore, it has also been demonstrated

\footnotetext{
${ }^{1}$ Department of Hematology, The First Affiliated Hospital of Xiamen University, Xiamen, China; ${ }^{2}$ Department of Hematology, Nanfang Hospital, Southern Medical University, Guangzhou, China and ${ }^{3}$ Research Institute in Healthcare Science, Faculty of Science and Engineering, University of Wolverhampton, Wolverhampton, UK ${ }^{*}$ Corresponding author: B Xu, Department of Hematology, The First Affiliated Hospital of Xiamen University, NO.55, Zhenhai Road, Xiamen 361003 , China. Tel: +86 592 5091 8842; Fax: +86 592 2139956. E-mail: xubingzhangjian@126.com

${ }^{4}$ These authors have contributed equally to this work.

Received 08.8.16; revised 20.3.17; accepted 21.3.17; Edited by H-U Simon
} 
that ROS-mediated apoptosis is closely associated with persistent activation of the JNK pathway. ${ }^{25,26}$

Nuclear factor- $\kappa \mathrm{B}(\mathrm{NF}-\kappa \mathrm{B})$, a transcription factor usually activated by inflammatory stimuli and cellular stresses, has a pivotal role in regulation of cell survival and growth. ${ }^{27} \mathrm{NF}-\mathrm{KB}$ has also been found to be essential for survival of cancer stem cells including LSCs, whereas inhibition of NF-KB triggers apoptosis of these cells. ${ }^{27}$ NF-E2-related factor-2 (Nrf2) is a transcription factor that mediates cytoprotective antioxidant responses and thus prevents cells from the damage induced by ROS and other harmful chemicals in various types of cancers. ${ }^{28}$ In addition to its tumorigenic function through stress responses, activation of Nrf2 is also associated with drug resistance to standard chemotherapy as well as with poor survival of cancer patients. ${ }^{29-31}$ Therefore, a possibility arises whether simultaneous inhibition of NF- $\kappa \mathrm{B}$ and Nrf2 might lead to increased efficacy of an antitumor agent, thereby representing an attractive and promising avenue to success of cancer treatment, particularly due to targeting these two signals crucial for survival of cancer stem cells like LSCs.

Here, we report that DS in combination with $\mathrm{Cu}$ has a potent and selective anti-leukemia property in vitro against leukemia stem-like cells (e.g., CD34 ${ }^{+} / \mathrm{CD}_{3} 8^{-} \mathrm{KG} 1 a$ and Kasumi- 1 cells and primary $\mathrm{CD} 34^{+}$cells isolated from $\mathrm{AML}$ patients) as well as is highly effective in vivo in $\mathrm{CD} 34^{+} / \mathrm{CD} 38^{-}$leukemic cell-derived xenograft mouse models, in association with induction of apoptosis via activation of the stress-related ROS-JNK pathway and inhibition of the pro-survival Nrf2 and NF- $K \mathrm{~B}$ pathways.

\section{Results}

Enrichment of leukemia stem-like cells from the human AML KG1a cell line. Leukemia stem-like cells were enriched from KG1a cell line, a subclone cell line of KG1 cells, by sorting a CD34 ${ }^{+} / \mathrm{CD}^{-} 8^{-}$cell population using fluorescenceactivated cell sorting (FACS). As shown in Figure 1a, percentage of the $\mathrm{CD} 34^{+} / \mathrm{CD} 38^{-}$population was significantly increased after sorted from KG1a cells $(93.2 \pm 2.7 \%$ versus $59.4 \pm 6.2 \%$ for KG1a cells before sorting; Figure 1a, right panel; $t=-8.675, P=0.001)$. As KG1a cells might have lost myeloid features (e.g., the pan-myeloid antigen MY9), ${ }^{32}$ we further performed flow cytometry to monitor the markers of myeloid cells. As shown in Figure $1 \mathrm{~b}$, these CD34 ${ }^{+} / \mathrm{CD} 38^{-}$ leukemia stem-like cells displayed positivity of the myeloid markers CD13 (99.1\%), CD33 (98.6\%), and CD123 (93.7\%), suggesting that certain myeloid features remain in these sorted CD34 ${ }^{+} / \mathrm{CD} 38^{-} \mathrm{KG} 1 \mathrm{a}$ cells.

$\mathrm{DS} / \mathrm{Cu}$ is cytotoxic against leukemia stem-like cells in vitro in a dose-dependent manner. First, we examined the cytotoxic effect of $\mathrm{DS} / \mathrm{Cu}$ on $\mathrm{CD} 34^{+} / \mathrm{CD} 38^{-}$leukemia stem-like cells sorted from KG1a cells by MTT assay. As shown in Figure 2a, after exposure to a series of the indicated concentrations of DS with or without $\mathrm{Cu}(1 \mu \mathrm{M})$ for $24 \mathrm{~h}$, inhibition of $\mathrm{CD} 34^{+} / \mathrm{CD}^{-} 8^{-}$cell proliferation was significantly increased in a dose-dependent manner, with $\mathrm{IC}_{50}$ value of $0.54 \pm 0.18 \mu \mathrm{M}$ for DS. Furthermore, this event was markedly enhanced by co-treatment with $\mathrm{Cu}$, with a reduction of $\mathrm{IC}_{50}$ values to $0.21 \pm 0.03 \mu \mathrm{M}(\mathrm{DS} / \mathrm{Cu}$ versus $\mathrm{DS}, t=3.107$, $P=0.036$ ), whereas treatment with $\mathrm{Cu}$ alone had no significant effect on cell proliferation (inhibition rate $=0.66 \pm$ $3.36 \%, P=0.748$ versus untreated control). Analogous results were obtained in leukemia stem-like cells sorted from Kasumi-1 cells, another human AML cell line, with $92.7 \pm 3.1 \%$ of $\mathrm{CD} 34^{+} / \mathrm{CD} 8^{-}$cells (Supplementary Figure 1A). As shown in Supplementary Figure 1B, the inhibitory effect on cell proliferation was significantly increased after exposed to DS in combination with $\mathrm{Cu}$ in a dose-dependent manner, compared with DS administrated alone.

To further confirm the cytotoxicity of DS/Cu, CD34 ${ }^{+} / \mathrm{CD} 38^{-}$ $\mathrm{KG} 1 a$ cells were treated with DS at different concentrations $(0.05,0.5,5 \mu \mathrm{M})$ in the presence or absence of $1 \mu \mathrm{M} \mathrm{Cu}$ for $24 \mathrm{~h}$, and then subjected to flow cytometric analysis after Annexin V/PI double staining. Administration of $\mathrm{Cu}$ alone failed to induce apoptosis, compared with untreated control $(5.6 \pm 4.0 \%$ versus $4.75 \pm 2.6 \%, t=0.474, P=0.66)$. However, co-exposure to different concentrations of DS and Cu resulted in significantly increased apoptosis in $\mathrm{CD} 34^{+} / \mathrm{CD} 38^{-}$cells (Figures $2 \mathrm{~b}$ and $\mathrm{c} ; P<0.01$ versus $\mathrm{DS}$ alone for each dose of DS). Similarly, in $\mathrm{CD}^{2} 4^{+} / \mathrm{CD} 38^{-}$Kasumi-1 cells, DS in combination with $\mathrm{Cu}(1 \mu \mathrm{M})$ also displayed a remarkably increased property of apoptosis induction in a dosedependently manner, whereas treatment with DS alone was barely able to trigger apoptosis (Supplementary Figure 1C; $\mathrm{DS} / \mathrm{Cu}$ versus $\mathrm{DS}$ alone, $P<0.05$ for each dose of DS).

We then examined whether DS/Cu would affect clonogenicity of leukemia stem-like cells, by the colony-forming assay. As shown in Figures $2 \mathrm{~d}$ and e, whereas treatment with $\mathrm{Cu}$ $(1 \mu \mathrm{M})$ alone had no effect on colony formation $(P=0.77$ versus untreated control), exposure to DS alone moderately inhibited colony formation was (mean colony-forming units (CFU) inhibition rate, $69.29 \pm 19.54 \%$ for $0.1 \mu \mathrm{M}$ DS, $P<0.05$ versus untreated control), which was sharply enhanced when $\mathrm{DS}$ and $\mathrm{Cu}$ were administrated together in $\mathrm{CD} 34^{+} \mathrm{CD} 38^{-}$ KG1a cells $(48.55 \pm 14.36 \%$ for $0.01 \mu \mathrm{M}$ DS, $P<0.05$ and $P<0.01$ versus untreated control and DS alone, respectively; $0.83 \pm 0.72 \%$ for $0.1 \mu \mathrm{M}$ DS, $P<0.001$ and $P<0.01$ versus untreated control and DS alone, respectively). Taken together, these results suggest that whereas DS itself displays noticeable dose-dependent cytotoxicity toward leukemia stem-like cells, while this effect is markedly potentiated when combined $\mathrm{DS}$ with non-toxic concentrations of $\mathrm{Cu}$.

DS/Cu-mediated cytotoxicity is dependent upon intracelIular ROS production in leukemia stem-like cells. Previous studies have indicated that generation of intracellular ROS is crucial for induction of apoptosis by chemotherapeutic agents in various types of cancers. ${ }^{33}$ To determine whether $\mathrm{DS} / \mathrm{Cu}$-induced apoptosis would rely on intracellular ROS production, we thus measured the ROS level in CD34 ${ }^{+} \mathrm{CD} 38^{-}$ KG1a cells after exposed to DS/Cu for 6, 12, 18, $24 \mathrm{~h}$, using the DCFH-DA-based assay. As shown in Figures $3 a$ and b, co-administration of $\mathrm{DS}(0.5 \mu \mathrm{M})$ and $\mathrm{Cu}(1 \mu \mathrm{M})$ resulted in a robust increase in intracellular ROS accumulation at different time points $(P<0.001$ for each interval except $6 \mathrm{~h}$, compared with untreated control and DS alone, respectively), in 

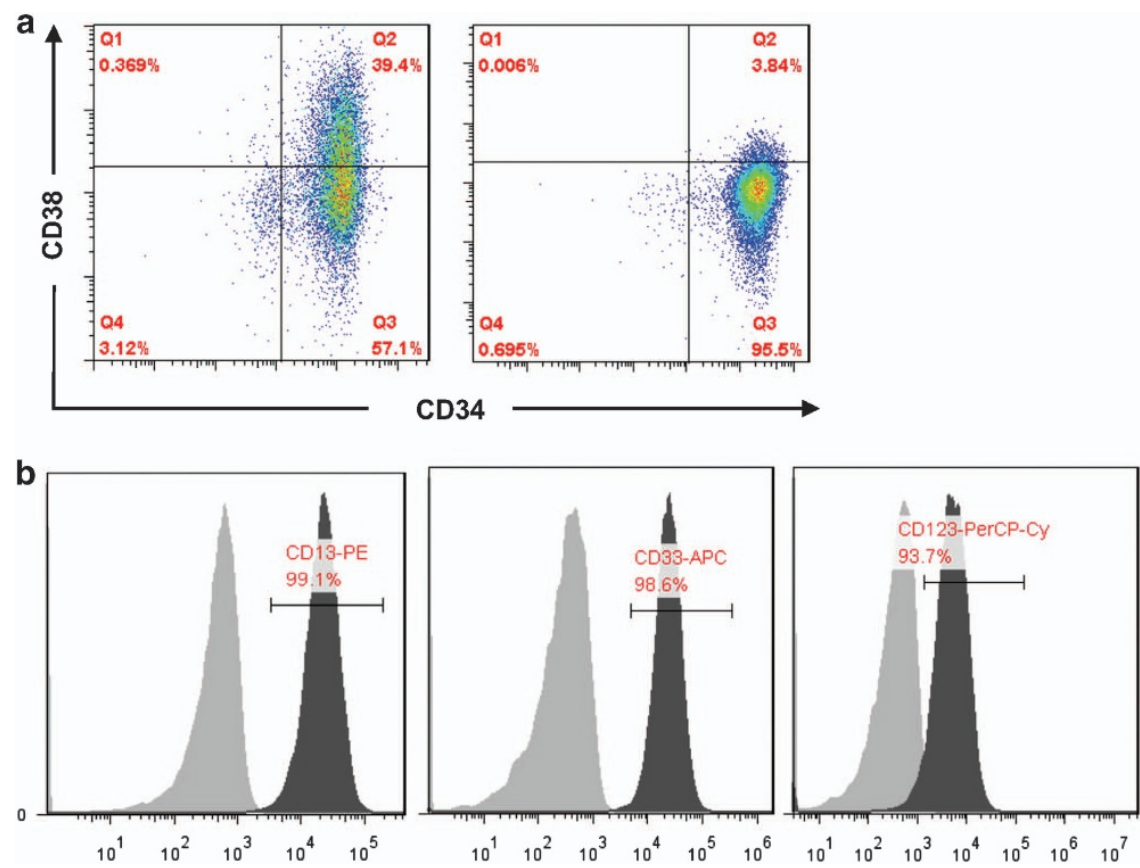

Figure 1 Enrichment of leukemia stem-like cells from KG1 $\alpha$ cell line. Percentage of CD34 $4^{+}$CD $38^{-}$population was analyzed by flow cytometry before (a, left panel) and after sorting (right panel). Before sorting, the $\mathrm{CD} 34^{+} / \mathrm{CD} 38^{-} \mathrm{KG} 1$ a cells were $59.4 \pm 6.2 \%$. After sorting, the percentage of $\mathrm{CD} 4^{+} / \mathrm{CD} 38^{-}$is $93.2 \pm 2.7 \%$. (b) Myeloid surface markers (CD13, CD33, and CD123) in sorted KG1a cells were detected by flow cytometry. The filled grey area represents isotype control staining

association with induction of apoptosis by DS/Cu (Figures $2 b$ and $c$ ).

We next investigated the functional role of ROS in induction of apoptosis by $\mathrm{DS} / \mathrm{Cu}$ in leukemia stem-like cells, by employing the free radical scavenger $\mathrm{N}$-acetyl-cysteine (NAC). Apoptosis was analyzed after co-exposed to different concentrations of DS and $\mathrm{Cu}(1 \mu \mathrm{M})$ in the presence or absence of NAC (10 mM) for $24 \mathrm{~h}$ in both CD34 ${ }^{+} / \mathrm{CD}^{-} 8^{-} \mathrm{KG} 1 \mathrm{a}$ and Kasumi-1 cells, respectively. As shown in Figure 3c, treatment with NAC clearly abrogated apoptosis induced by DS/Cu in $\mathrm{CD}^{+} 4^{+} / \mathrm{CD}_{3} 8^{-} \mathrm{KG} 1$ a cells $(P<0.05$ versus $\mathrm{DS} / \mathrm{Cu}$ for each dose of DS), whereas NAC itself had almost no effect on apoptosis $(P=0.762$ versus untreated control). Moreover, identical treatment with $\mathrm{NAC}$ also partly rescued $\mathrm{CD} 34^{+}$ /CD38 ${ }^{-}$Kasumi-1 cells from apoptosis induced by DS/Cu as shown in Supplementary Figures1E and 1F $(P<0.05$ for each group, DS/Cu/NAC versus DS/Cu).

The similar results were also obtained in primary CD34 ${ }^{+}$ cells isolated from bone marrow samples of the AML patients \#3, \#4, \#5, and \#11. As shown in Figures 3d-f, after exposure to $\mathrm{DS}(0.1 \mu \mathrm{M})$ with or without $\mathrm{Cu}(1 \mu \mathrm{M})$ for $6 \mathrm{~h}$, a significant increase in intracellular ROS level was observed in primary CD34 $^{+}$AML cells $(P<0.01$, DS/Cu versus untreated control; $P<0.05$, DS $/ \mathrm{Cu}$ versus DS alone). Furthermore, coadministration with NAC also remarkably abolished apoptosis induced by $\mathrm{DS} / \mathrm{Cu}$ in primary CD34 ${ }^{+} \mathrm{AML}$ cells $(P=0.001$ for $\mathrm{DS} / \mathrm{Cu}$ versus untreated control; $P=0.003 \mathrm{DS} / \mathrm{Cu} / \mathrm{NAC}$ versus $\mathrm{DS} / \mathrm{Cu}$ ), whereas NAC itself did not affect apoptosis ( $P=0.947$ versus untreated control). Together, these results suggest that DS/Cu-induced apoptosis in leukemia stem-like cells is highly dependent on generation of intracellular ROS.
DS/Cu inhibits the Nrf2 and NF-kB pathways as well as activates the JNK pathway in leukemia stem-like cells. Given the previous observations that ROS-mediated apoptosis highly relies on activation of JNK, the effect of DS/Cu on the JNK pathway was assessed in $\mathrm{CD}_{3} 4^{+} / \mathrm{CD} 38^{-} \mathrm{KG} 1 \mathrm{a}$ cells. As shown in Figure $4 a$, exposure to DS resulted in a clear increase in phosphorylation of both JNK (p-JNK) and its downstream target $c-j u n$ ( $p-c-j u n)$, which was remarkably enhanced by co-administration of $\mathrm{Cu}$.

Previous reports have also demonstrated that DS inhibits $N F-\kappa B$, in association with its potent antitumor activity. ${ }^{34}$ Notably, treatment with DS alone for $24 \mathrm{~h}$ effectively downregulated the expression of p65, a core component of the NF- $\kappa \mathrm{B}$ family, accompanied by markedly reduced expression of the NF- $K B$ target genes survivin and $c-m y c$, and these events were clearly enhanced when DS was administrated with $\mathrm{Cu}$ in combination (Figure $4 \mathrm{~b}$ ).

As Nrf2 has an important role in activation of antioxidant responses to $\mathrm{ROS},{ }^{8} \mathrm{Nrf} 2$ and its downstream gene expression was monitored by western blot analysis and RT-PCR after exposed to DS $(0.5 \mu \mathrm{M})$ with or without $\mathrm{Cu}(1 \mu \mathrm{M})$ for $24 \mathrm{~h}$. Treatment with DS or DS/Cu significantly reduced the protein level of Nrf2 in $\mathrm{CD}^{2} 4^{+} / \mathrm{CD} 38^{-} \mathrm{KG} 1 \mathrm{a}$ cells (Figure $\left.4 \mathrm{c}\right)$. Of note, whereas DS or $\mathrm{Cu}$ alone displayed a modest effect $(P>0.05$ versus untreated control), combined administration of $\mathrm{DS} / \mathrm{Cu}$ dramatically inhibited the expression of the Nrf2 downstream genes, including $\mathrm{HO}-1, \mathrm{NQO} 1$, and $\mathrm{GSR}$, in $\mathrm{CD} 34^{+} / \mathrm{CD} 38^{-}$ KG1 a cells (Figure 4d).

Comparable results were also observed in primary $\mathrm{CD} 34^{+}$ cells isolated from bone marrow samples of the AML patient \#2 and patient \#5. As shown in Figures $4 \mathrm{f}$ and $\mathrm{g}$, ex vivo treatment with DS/Cu resulted in a sharp decrease in the 
a

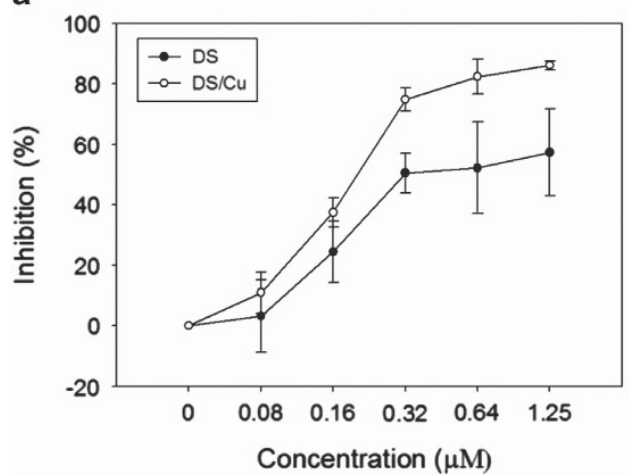

b

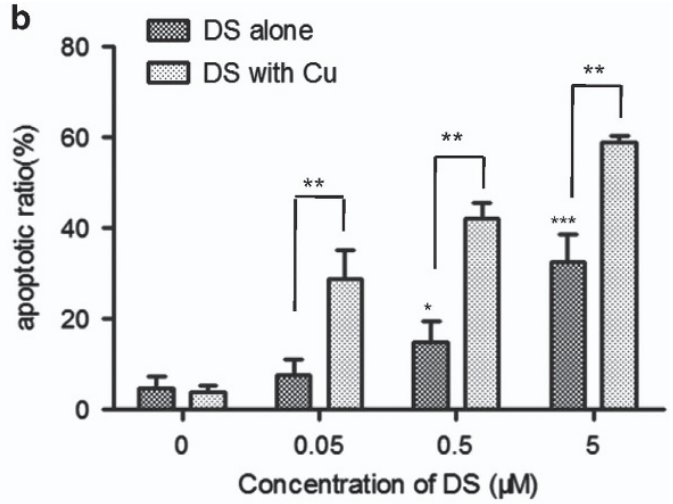

C
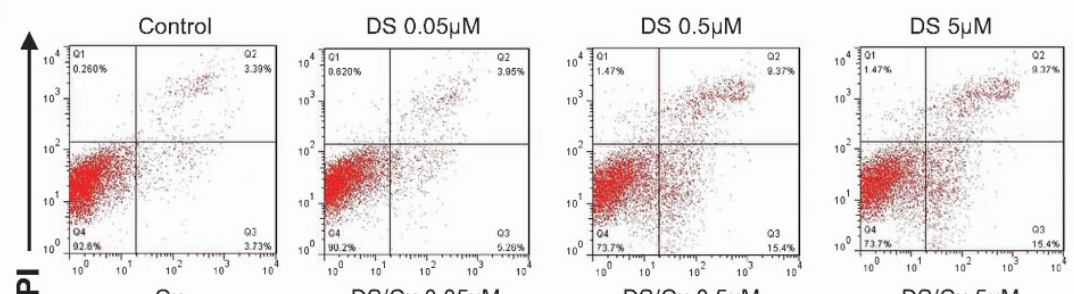

$\bar{a}$

$\mathrm{Cu}$
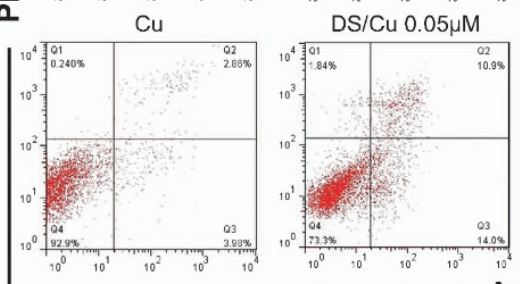

DS/Cu $0.5 \mu \mathrm{M}$
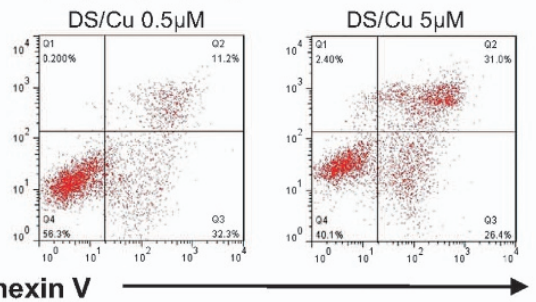

d

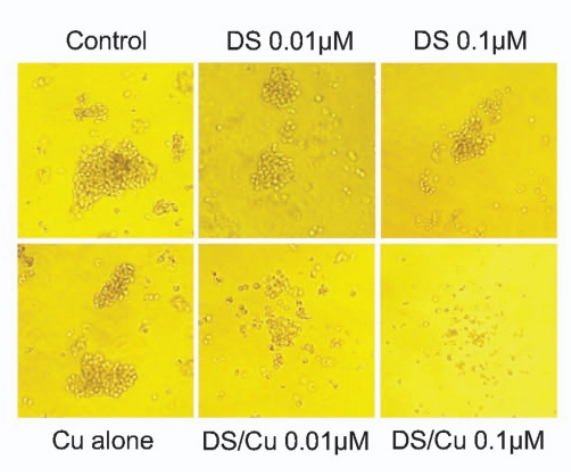

e

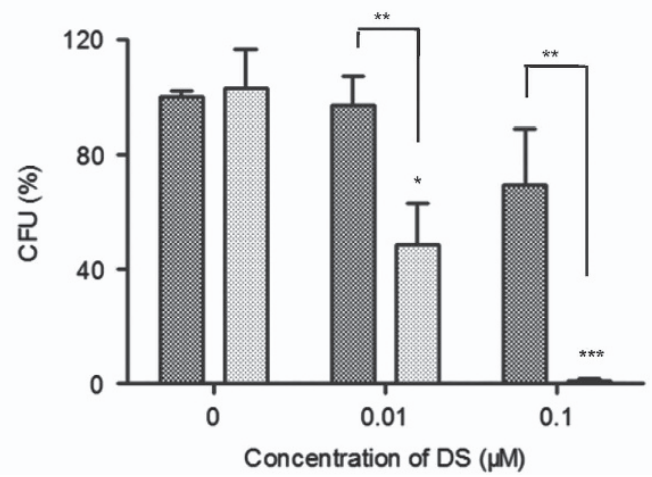

Figure 2 DS/Cu is cytotoxic toward leukemia stem-like cells in vitro. (a) Dose-dependent DS/Cu-induced effect on cell proliferation. (b) Histogram of apoptosis percentage in $\mathrm{CD} 34^{+} / \mathrm{CD} 38^{-} \mathrm{KG} 1$ la leukemia stem-like cells. ${ }^{* *} P<0.01$. (c) Representative data for flow cytometric analysis of Annexin V/PI dual staining in $\mathrm{CD}^{2} 4^{+} / \mathrm{CD} 38^{-} \mathrm{KG} 1 \mathrm{a}$ cells after treated with indicated concentrations of DS with or without $\mathrm{Cu}(1 \mu \mathrm{M})$ for $24 \mathrm{~h}$. (d) Dose-dependent effect on colony-forming ability after treatment with DS or DS/Cu for $18 \mathrm{~h}$. (e) Histogram of colony-forming ability in $\mathrm{CD} 34^{+} / \mathrm{CD} 38^{-} \mathrm{KG1}$ a cells. ${ }^{*} P<0.05,{ }^{* \star} P<0.01,{ }^{* * *} P<0.001$. Data were presented as mean $\pm S$.D. for three independent experiments

protein level of p65 in both patient samples, whereas DS and/ or $\mathrm{Cu}$ alone or in combination also increased phosphorytions of p-JNK (particularly p46 isoform) and p-c-jun (36 kDa, lower band), as well as downregulated Nrf2 in these samples in primary $\mathrm{CD} 34^{+} \mathrm{AML}$ cells.

The free radical scavenger NAC reverses the DS/Cuinduced alterations in the Nrf2 and JNK pathways. To examine a possibility whether the alterations of Nrf2 expression and JNK activation would be linked to ROS, NAC
$(10 \mathrm{mM})$ was used to test the role of ROS in these events induced by $\mathrm{DS} / \mathrm{Cu}$. As shown in Figure 4e, downregulation of Nrf2 and phosphorylation of JNK induced by DS/Cu were markedly blocked by NAC in $\mathrm{CD} 34^{+} \mathrm{CD} 38^{-} \mathrm{KG} 1 a$ cells, suggesting that ROS might act upstream of the Nrf2 and JNK pathways in leukemia stem-like cells treated with $\mathrm{DS} / \mathrm{Cu}$.

DS/Cu selectively targets primary CD34+ ${ }^{+}$ML stem-like cells while sparing normal hematopoietic progenitor cells. To validate the activity of $\mathrm{DS} / \mathrm{Cu}$ against leukemia 
a
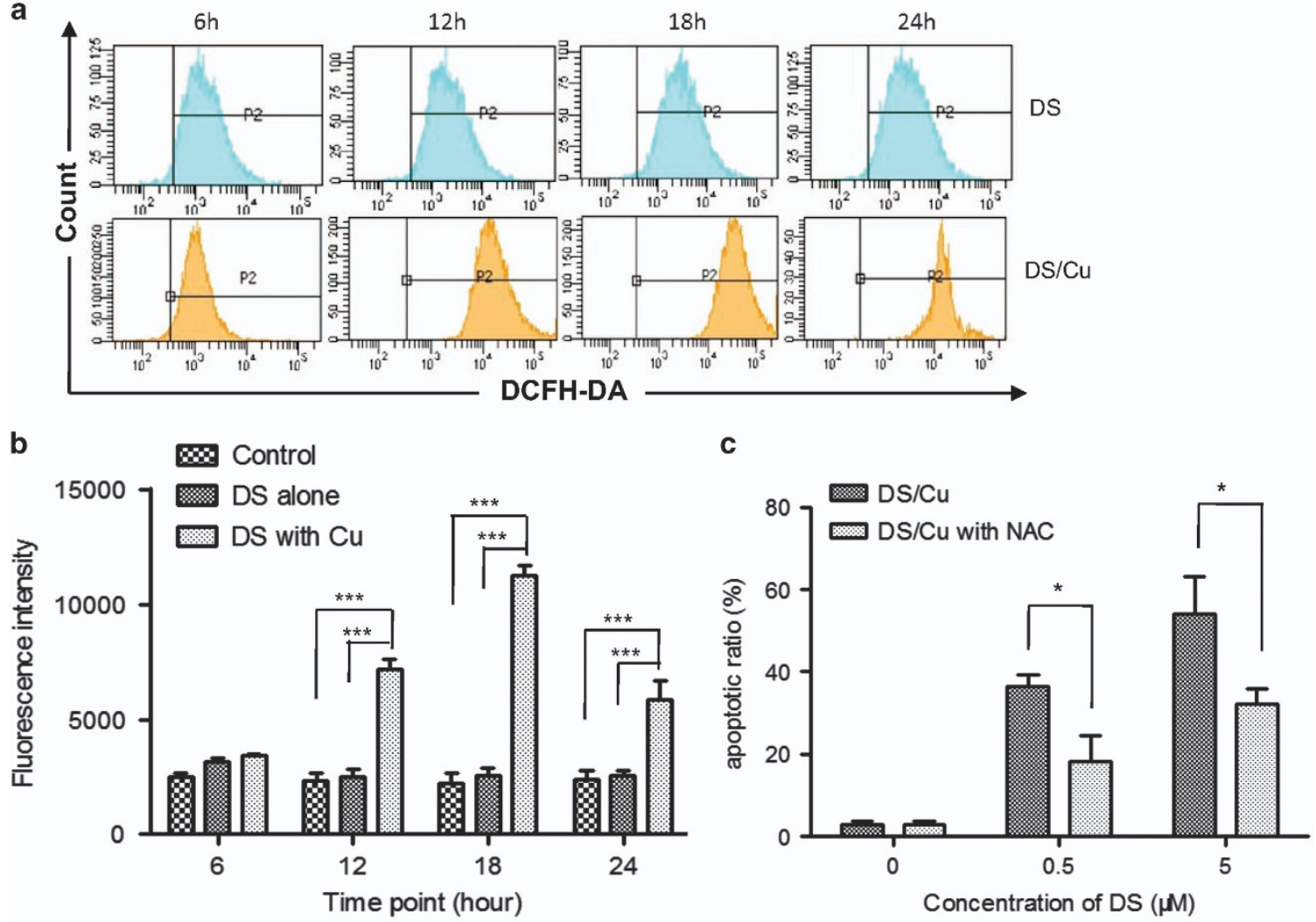

d
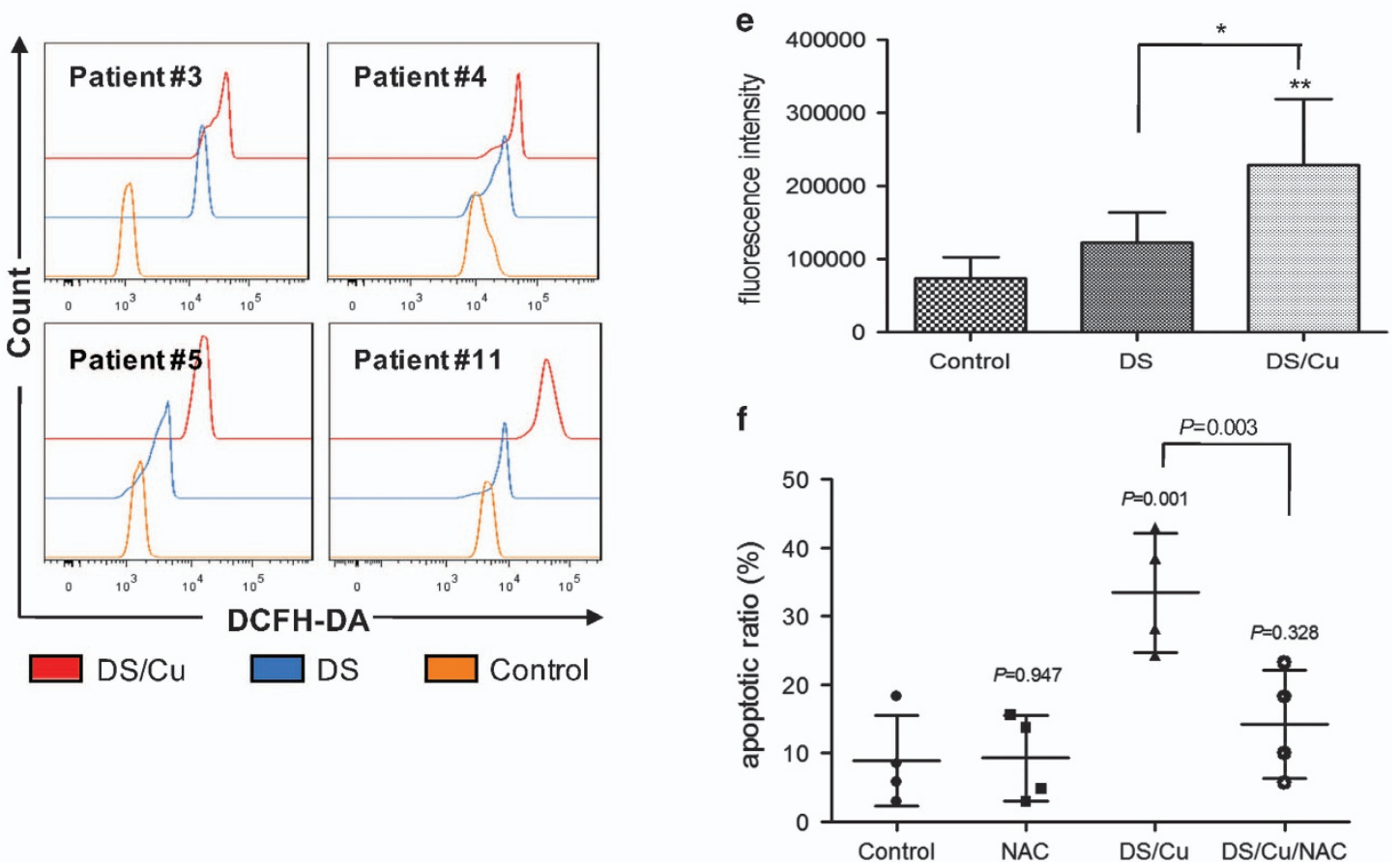

Figure 3 DS/Cu-induced cytotoxicity is associated with intracellular ROS accumulation in leukemia stem-like cells. (a) CD34 $4^{+} / C^{2} 38^{-}$KG1a cells were treated with DS $(0.5 \mu \mathrm{M}) \pm \mathrm{Cu}(1 \mu \mathrm{M})$ for the indicated intervals. Intracellular ROS level was determined by analysis of DCFH-DA fluorescence intensity. (b) Histogram of ROS generation in $\mathrm{CD} 34^{+} / \mathrm{CD} 38^{-} \mathrm{KG1a}{ }^{* \star *} P<0.001$. (c) Histogram of apoptosis percentage in $\mathrm{CD} 34^{+} / \mathrm{CD} 38^{-} \mathrm{KG} 1 \mathrm{a}$ cells in the presence of free radical scavenger NAC (10 mM) $\pm \mathrm{DS} / \mathrm{Cu}$ for $24 \mathrm{~h}$. ${ }^{*} P<0.05$. (d) Intracellular ROS level was examined by analysis of DCFH-DA fluorescence intensity. Primary CD34 ${ }^{+}$samples isolated from AML patient \#3, \#4, \#5, \#11 were treated with DS $(0.1 \mu \mathrm{M})+/-\mathrm{Cu}(1 \mu \mathrm{M})$ for $6 \mathrm{~h}$. ${ }^{*} P<0.05,{ }^{* \star} P<0.01$. (e) Histogram of ROS generation in CD34 ${ }^{+}$primary cells $(n=4)$. (f) Histogram of apoptosis percentage in $\mathrm{CD} 34^{+}$primary cells $(n=4)$ after treated with $\mathrm{DS} / \mathrm{Cu}$ or $\mathrm{DS} / \mathrm{Cu} / \mathrm{NAC}$ 
a
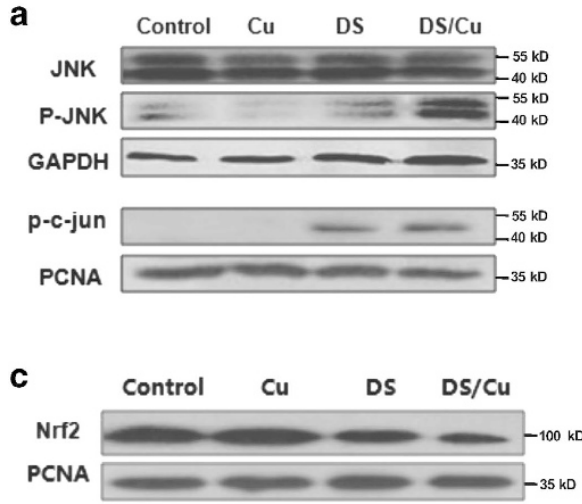

e

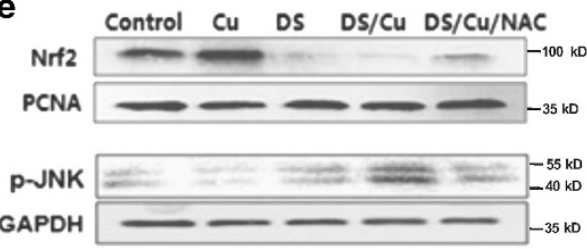

f

$\mathrm{CD} 4^{+}$cells from Patient \#2

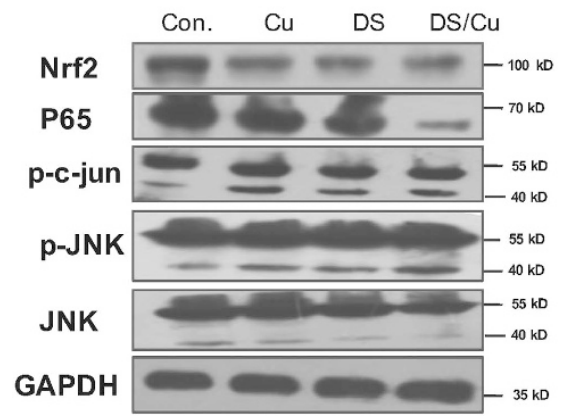

b

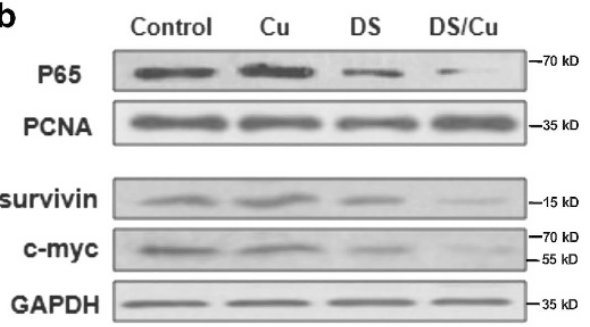

d Control $\square$ DS alone
$\square$ Cu alone $\square$ DS with $\mathrm{Cu}$

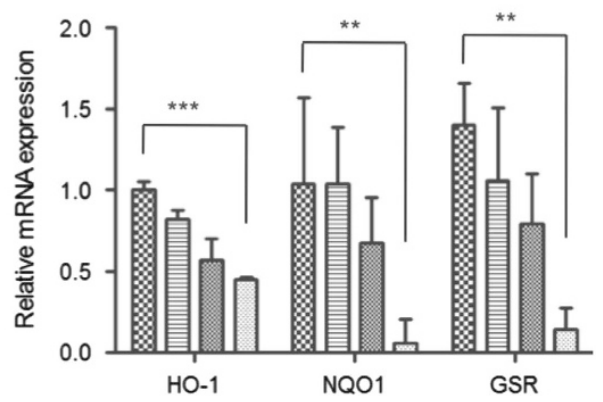

g $\quad$ CD34 ${ }^{+}$cells from Patient \#5

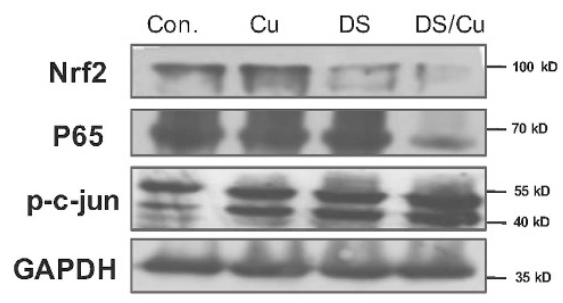

Figure 4 DS in combination with Cu suppresses expression of Nrf2 and NF- $\kappa B$ while activates the JNK pathway in leukemia stem-like cells. (a, b) CD34 $/ C D 38^{-} K G 1 \alpha$ cells were incubated with $0.5 \mu \mathrm{M} \mathrm{DS} \pm 1 \mu \mathrm{M}$ Cu for $24 \mathrm{~h}$, flowed by western blot analysis to monitor expression of the JNK (a) and NF- $k \mathrm{~B}$ (b) pathway-related proteins. (c) Western blotting analysis of Nrf2 protein level in CD34 $/ C D 38^{-} \mathrm{KG} 1 \alpha$ cells after DS or DS/Cu treatment for $24 \mathrm{~h}$. (d) Relative mRNA expression of downstream genes (HO-1, NQO1 and GSR) of the Nrf2 pathway in $\mathrm{CD} 34^{+} / \mathrm{CD} 38^{-} \mathrm{KG} 1 \alpha$ cells. Data were presented as mean \pm S.D. of three independent experiments. ${ }^{* *} P<0.01,{ }^{* *} P<0.001$. (e) Western blot analysis for the expression of Nrf2 and p-JNK in CD34 $4^{+}$CD38 ${ }^{-}$KG1 $\alpha$ cells after co-treatment with DS/Cu and NAC. (f, $\left.\mathbf{g}\right)$ Western blot analysis for the detection of JNK, Nrf2, and P65 pathway expression in primary CD34 $4^{+} \mathrm{AML}$ cells isolated from patient \#2 (f) and patient \#5 (g), after exposure to DS with or without Cu for $24 \mathrm{~h}$

stem-like cells, CD34 ${ }^{+}$cells were isolated by magnetic activated cell sorter (MACS) from AML patients and healthy donors for hematopoietic stem cell transplantation, respectively. Clinical characteristics of these AML patients are summarized in Table 1. Consistent with the anti-leukemia effect of $\mathrm{DS} / \mathrm{Cu}$ observed in $\mathrm{CD} 34^{+} / \mathrm{CD} 38^{-} \mathrm{KG} 1 a$ cells, treatment with $0.5 \mu \mathrm{M}$ DS with or without $1 \mu \mathrm{M} \mathrm{Cu}$-induced apoptosis of $\mathrm{CD}_{4} 4^{+} \mathrm{AML}$ cells (Figure $5 \mathrm{a} ; P=0.012$ and $P<0.001$ DS and DS/Cu versus untreated control, respectively; $n=14)$, whereas $\mathrm{Cu}$ alone $(1 \mu \mathrm{M})$ was unable to induce apoptosis $(15.92 \pm 12.1 \%$ versus $11.45 \pm 6.8 \%$ for $\mathrm{Cu}$ alone versus untreated control, $P=0.966)$. Of note, although administration of DS alone at low doses (e.g., $0.1 \mu \mathrm{M})$ did not significantly induced apoptosis $(P=0.52$, compared with untreated control), combined treatment with $\mathrm{Cu}(1 \mu \mathrm{M})$ led to a marked increase in apoptosis of $\mathrm{CD}_{3} 4^{+} \mathrm{AML}$ cells
(Figure 5a; $P=0.009$ for $\mathrm{DS} / \mathrm{Cu}$ versus untreated control). In sharp contrast, the identical treatment failed to induce apoptosis in normal $\mathrm{CD} 34^{+}$hematopoietic cells (Figure 5b; $P>0.05$ for $\mathrm{DS} / \mathrm{Cu}$ versus untreated control in all cases).

Three patients (\#7, 8, and 12) with secondary AML (SAML) evolved from a preceding phase of myelodysplastic syndrome (MDS) were also enrolled in the present study. Unexpectedly, consistent with the ex vivo activity in primary samples from AML patients, DS/Cu also exhibited a potent antitumor activity against $\mathrm{CD} 34^{+}$cells isolated from these three patients with sAML $(49.4 \pm 14.5 \%$ and $67.8 \pm 21.5 \%$ versus $10.6 \pm 8.3 \%$ for $0.5 \mu \mathrm{M}$ DS alone and $0.5 \mu \mathrm{M} \mathrm{DS} / 1 \mu \mathrm{M} \mathrm{Cu}$ versus untreated control, $P=0.002$ and $P<0.001$, respectively). Further twoway analysis of variance (ANOVA) analysis revealed no significant difference in the cytotoxic effect of DS/Cu between $\operatorname{sAML}(n=3)$ and primary $\operatorname{AML}(n=11 ; P=0.62)$. 


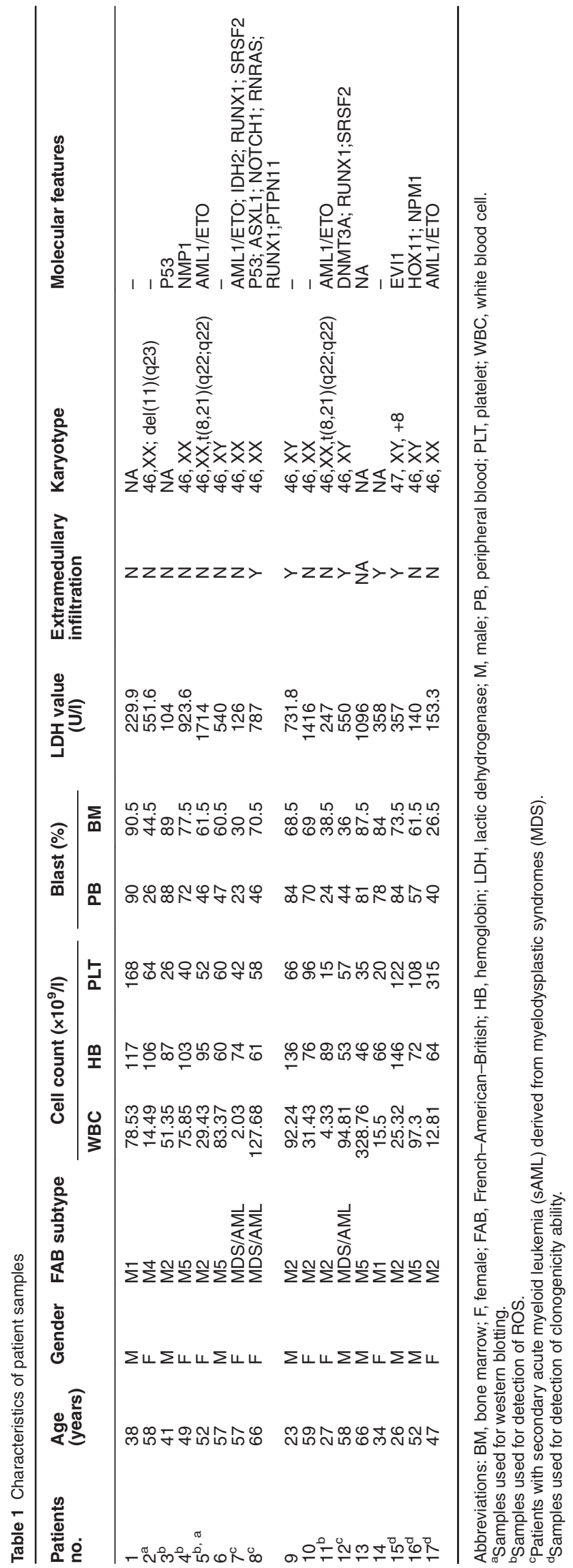

Colony formation assay was then carried out to assess clonogenicity of primary $\mathrm{CD} 34^{+} \mathrm{AML}$ stem-like cells and $\mathrm{CD} 4^{+}$normal hematopoietic cells, respectively. As shown in Figure $5 \mathrm{c}$, DS alone at low doses $(0.05 \mu \mathrm{M}$ and $0.1 \mu \mathrm{M})$ significantly reduced the number of CFU of primary CD34 AML cells after cultured for $10-14$ days $(P<0.05$ and $P<0.01$ for $0.05 \mu \mathrm{M}$ and $0.1 \mu \mathrm{M}$ versus untreated control, respectively), whereas combined treatment with DS and $\mathrm{Cu}(1 \mu \mathrm{M})$ further reduced the number of CFU $(P<0.01$ versus untreated control in all cases). It is noteworthy that the identical treatment with DS alone or DS/Cu exhibited almost no effect on the number of $\mathrm{CFU}$ of normal $\mathrm{CD}^{+}{ }^{+}$hematopoietic cells (Figure 5d; $P>0.05$ versus untreated control for each condition). Therefore, these findings suggested that $D S / C u$ might have highly effective anti-leukemia activity against leukemia stem-like cells, with low toxicity toward normal hematopoietic progenitor cells.

DS/Cu suppresses growth of xenograft derived from $\mathrm{CD} 4^{+} / \mathrm{CD}^{-} 8^{-}$leukemia stem-like cells. Last, to assess in vivo antitumor effects of DS/Cu, CD34 ${ }^{+} / \mathrm{CD} 38^{-} \mathrm{KG} 1 a$ cells were grafted in mice to a leukemia mouse model as described in detail in Methods. As shown in Figure 6a, a significant inhibition of tumor growth was observed after $\mathrm{DS} / \mathrm{Cu}$ treatment, arguing the antitumor activity of $\mathrm{DS} / \mathrm{Cu}$ in vivo. Average body weight of mice treated with vehicle (PBS) was $17.80 \pm 0.41 \mathrm{~g}$ after 2 weeks, whereas was $18.07 \pm 0.35 \mathrm{~g}$ and $19.02 \pm 0.39 \mathrm{~g}$ for Ara-C group and $\mathrm{DS} / \mathrm{Cu}$ group, respectively $(P<0.05$ for $\mathrm{DS} / \mathrm{Cu}$ group versus the group of mice received either vehicle or Ara-C, a standard agent currently used to treat AML in clinic). In addition, treatment with either $\mathrm{DS} / \mathrm{Cu}$ and Ara-C remarkably reduced tumor burden, manifested by a significant decrease in percentage of blast cells in bone marrow (Figure 6b; $24.73 \pm 1.48 \%$ for DS/Cu group versus $34.96 \pm 1.94 \%$ for vehicle group, $P<0.001 ; 24.56 \pm 2.25 \%$ for Ara-C group versus $34.96 \pm 1.94 \%$ for vehicle group, $P<0.001)$. However, there was no statistically significant difference between DS/Cu and Ara-C groups $(P>0.05)$. Moreover, HE staining and immunohistochemistry for human CD45 at 6th week following transplantation demonstrated that the ability of blast cells to invade liver and spleen was remarkably impaired in mice treated with $\mathrm{DS} / \mathrm{Cu}$ or Ara-C, compared with those in mice received vehicle as control (Figure 6c). Finally, western blot analysis revealed that treatment with DS/Cu also reduced Nrf2 protein level in spleen cells (Figure 6d), consistent with the results observed in vitro.

\section{Discussion}

Development of new drug is a costly and time-consuming process. Therefore, exploring new functions for existing drugs, termed repurposing or repositioning, has attracted great attention owing to low cost and fast track. DS, a member of the dithiocarbamate family and which is an aldehyde dehydrogenase inhibitor and a $\mathrm{Cu}$ chelator, has been approved by FDA for the treatment of alcoholism for more than six decades. ${ }^{9,10} \mathrm{Cu}$ is an essential trace element for tumor cell proliferation and thus could serve as a selective 
a

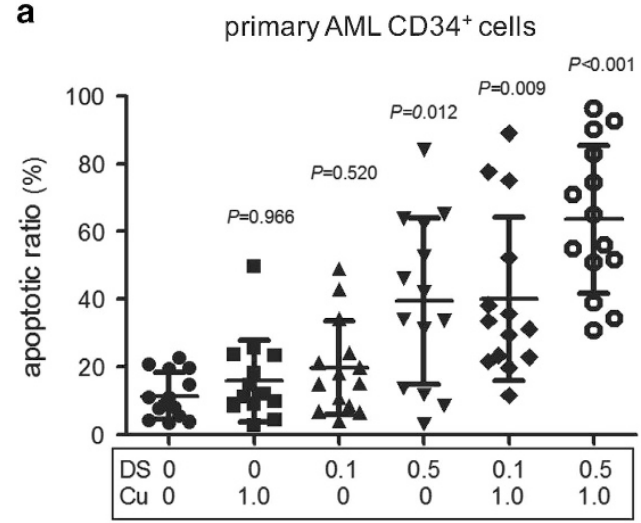

Concentration $(\mu \mathrm{M})$

C

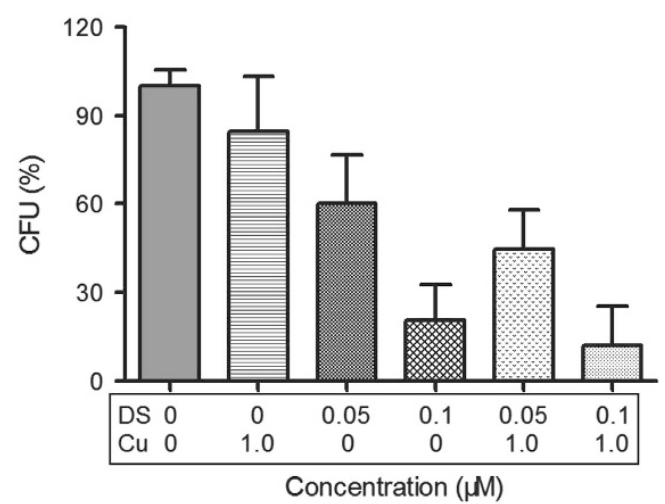

b Normal CD $34^{+}$hematopoietic cells

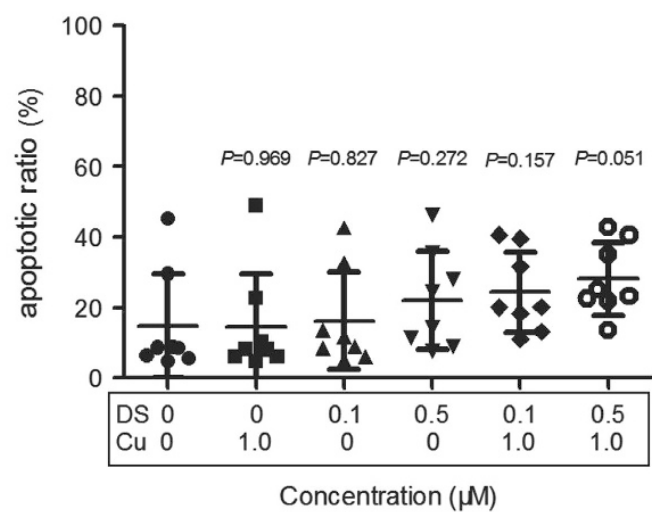

d

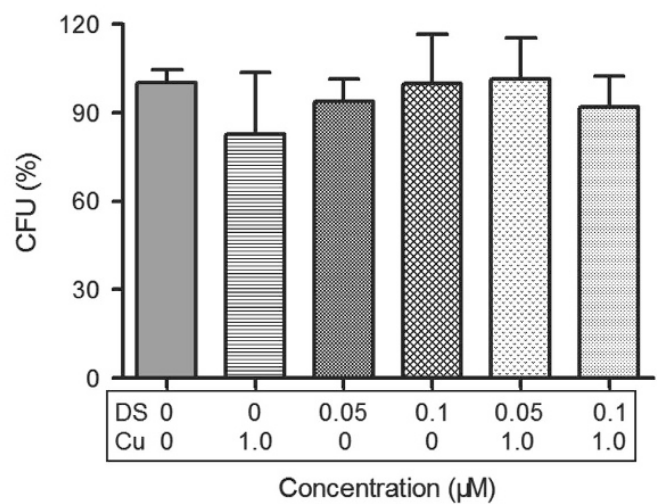

Figure 5 DS/Cu selectively kills primary CD34 ${ }^{+}$AML patients cells while sparing normal hematopoietic progenitor cells. (a, $\left.\mathbf{b}\right)$ Histogram of apoptosis percentage in primary $\mathrm{CD} 34^{+} \mathrm{AML}$ cells (a) and normal CD34 ${ }^{+}$hematopoietic cells (b) after exposure to indicated concentrations of DS with $1.0 \mu \mathrm{M}$ Cu for $24 \mathrm{~h}$. Each symbol represents results for an individual. Horizontal lines indicate the mean and SD for 14 AML patients and 8 healthy donors. (c, d) Histogram of colony-forming ability of primary CD34 ${ }^{+}$AML cells (c) and normal CD34 ${ }^{+}$hematopoietic cells (d) after treatment with DS or DS/Cu for $18 \mathrm{~h}$, compared with untreated control. Data were presented as mean \pm S.D. for three AML patients and three healthy donors

target for cancer therapies. ${ }^{22}$ Despite the concept of using $\mathrm{Cu}$ to tackle cancer that was proposed many decades ago, intracellular transport of $\mathrm{Cu}$ remains a major hurdle for its clinical application. However, this problem might be solved by combination of $\mathrm{Cu}$ with $\mathrm{DS}$, as the derivative $\mathrm{N}, \mathrm{N}$-diethyldithiocarbamte (deDTC) of DS can bind to $\mathrm{Cu}$ to form a $\mathrm{Cu}$ $(\text { deDTC })_{2}$ complex and thereby improve the intracellular trafficking of $\mathrm{Cu}{ }^{13}$

Recently, the anticancer activity of DS have attracted many attentions in various types of cancers. Here, we demonstrated that DS, particularly when co-administrated with non-toxic concentrations of $\mathrm{Cu}$ (e.g., $1 \mu \mathrm{M})$, was highly cytotoxic to leukemia stem-like cells, including CD $34^{+} / \mathrm{CD}^{-} 8^{-} \mathrm{KG} 1 \mathrm{a}$ cells and $\mathrm{CD} 34^{+} / \mathrm{CD} 38^{-}$Kasumi- 1 , as well as primary $\mathrm{CD} 34^{+}$cells isolated from $A M L$ patients, in a dose-dependent manner, whereas largely sparing normal hematopoietic progenitor cells. Compared with normal cells, AML cells might generally have higher level of $\mathrm{Cu}$, which enables DS to target AML cells selectively. The present in vitro results indicate that in the absence of $\mathrm{Cu}$, the concentration of DS required for antitumor action was markedly higher than that in the presence of $\mathrm{Cu}$ $(0.54 \mu \mathrm{M}$ versus $0.21 \mu \mathrm{M})$ in $\mathrm{CD}^{+} 4^{+} \mathrm{CD} 38^{-} \mathrm{KG} 1 \mathrm{a}$ cells, suggesting the necessity of free $\mathrm{Cu}$ in the cytotoxic effect of $\mathrm{DS} / \mathrm{Cu}$ in combination. Of note, $\mathrm{IC}_{50}$ of $\mathrm{DS}$ in combination with non-toxic $\mathrm{Cu}$ against leukemia stem-like cells was significantly lower than the concentration recommended for alcoholism treatment (500 mg as maximum daily dosage), ${ }^{35}$ implying high antitumor efficacy but low non-specific toxicity of DS. In addition to the anti-proliferation function, DS/Cu also had a marked effect on both induction of apoptosis and impairment of clonogenicity of leukemia stem-like cells, including primary $\mathrm{CD}^{+} 4^{+} \mathrm{AML}$ cells, with minimally toxicity towards normal counterparts obtained from healthy donors. We also obtained encouraging results in xenograft animal models derived from leukemia stem-like cells, reflected by both reduction of tumor burden as well as inhibition of blast cell invasion into vital organs such as liver and spleen. Together, these findings argue that DS/Cu has a promising potential to be safely used to treat $A M L$ in clinic.

SAML is a poorly defined term that often refers to $A M L$ developed following a previous disease, such as MDS or chronic myeloproliferative disorder. ${ }^{36}$ Approximately $30 \%$ of patients with MDS will develop to AML, especially those with high-risk MDS. Poor clinical outcomes for this large and 
variable group of patients with sAML are associated with greater incidence of chemo-resistance compared with those with de novo AML. Interestingly, the marked ex vivo activity of $\mathrm{DS} / \mathrm{Cu}$ was observed in $\mathrm{CD}_{3}{ }^{+}$cells isolated from patients with SAML developed from MDS, without any significant difference compared with those from patients with primary $A M L$, suggesting that patients with $S A M L$ might be also susceptible to DS/Cu treatment. However, although the role of
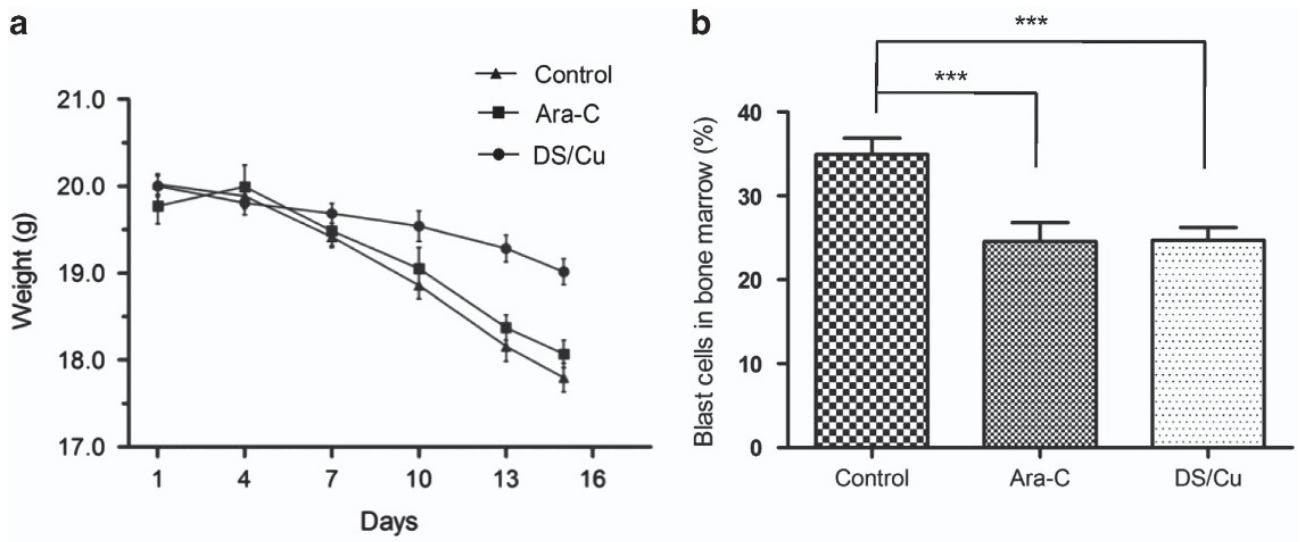

C
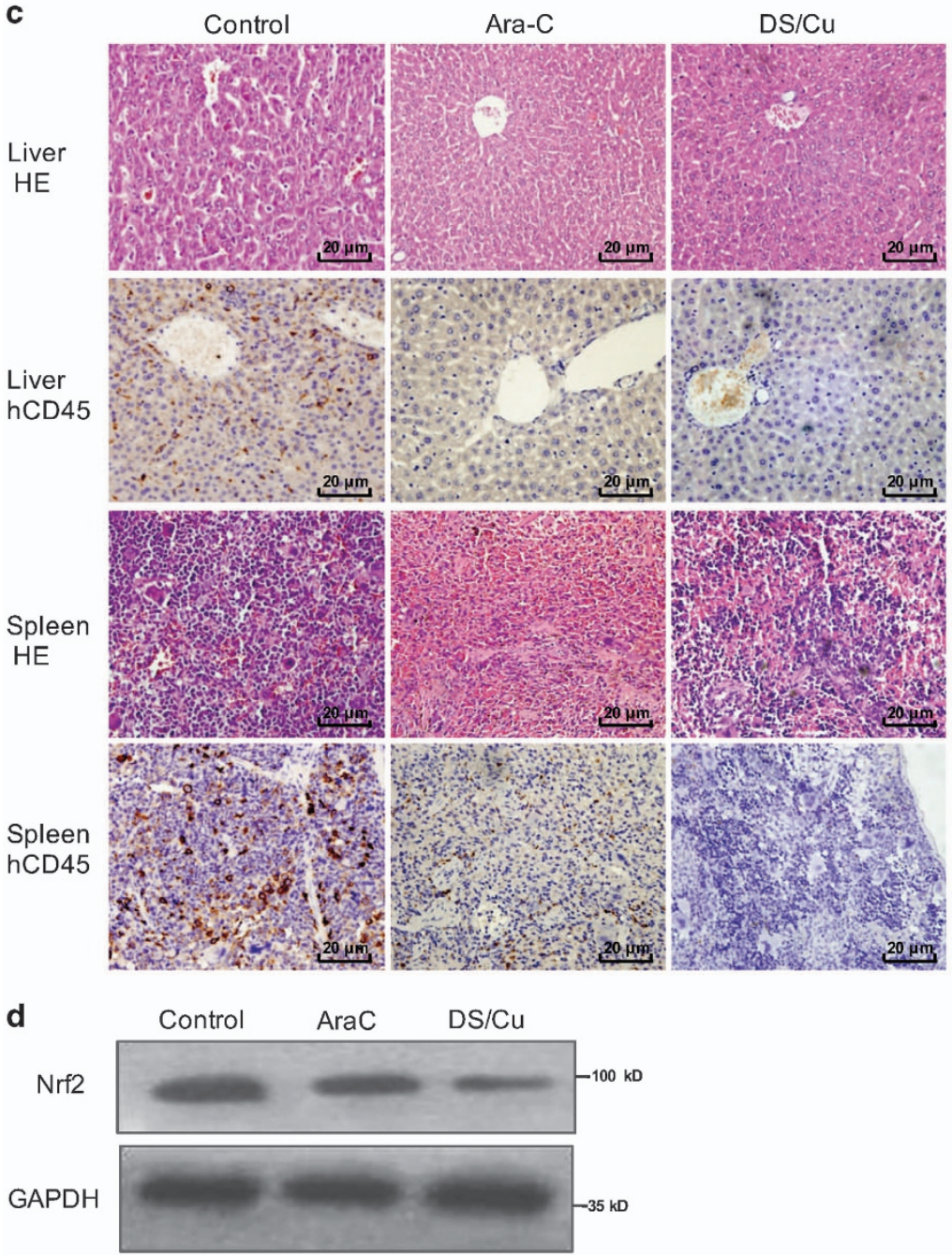

Figure 6 DS/Cu suppresses growth of xenograft derived from leukemia stem-like cells. An xenograft model was established in NOD/SCID mice 4 weeks after inoculation of $\mathrm{CD}^{+} 4^{+} / \mathrm{CD} 38^{-} \mathrm{KG1a}$ leukemia stem-like cells. Mice were randomly divided into DS/Cu group, Ara-C group and control group (eight per group). (a) Body weight changes of mice received different treatments. (b) Histogram of proportion of blast cells in bone marrow evaluated microscopically after Wright staining. ${ }^{\star \star \star} P<0.001$. (c) Paraffin-embedded sections of spleen and liver from mice were subjected to H\&E staining and immunohistochemcal staining for hCD45 (x400). (d) Western blot analysis of spleen extracts from mice using anti-Nrf2 antibody 
$\mathrm{DS} / \mathrm{Cu}$ in patients with $\mathrm{SAML}$ remains to be defined in a larger sample size of study, this finding provides initial evidence for further exploration of $\mathrm{DS} / \mathrm{Cu}$ in treatment of $\mathrm{SAML}$ evolved from MDS.

It is well characterized that antitumor activity of most chemotherapeutic agents is closely related to both generation of ROS and disruption of redox homeostasis. As a consequence, ROS induces collapse of mitochondria membrane potential, thereby triggering a series of mitochondriaassociated events including apoptosis. ${ }^{37}$ In consistence with these results, measurement of ROS level in leukemia stemlike cells indicated that exposure to $\mathrm{DS} / \mathrm{Cu}$ led to a marked intracellular ROS burst, which functionally contribute to DS/Cu-induced apoptosis, manifested by the abrogation of cell death by the antioxidant NAC. Moreover, it has been reported that ROS is a potent activator of JNK through oxidative inactivation of endogenous JNK inhibitors, such as JNK phosphatases and glutathione S-transferase $\pi .^{19}$ The results of the present study indicated that sustained activation of the JNK pathway (e.g., phosphorylation of JNK and c-Jun) was induced by $\mathrm{DS} / \mathrm{Cu}$ in leukemia stem-like cells while reversed by NAC that inhibited ROS production, supporting a notion that ROS-activated JNK signal might be, at least in part, responsible for DS/Cu-induced apoptosis.

It has widely accepted that in addition to induction of ROS, the effect of anti-neoplastic agents is also associated with their capability to inhibit activity of pro-survival transcription factors and antioxidants. NF- $k$ B is known to be aberrantly activated in several types of tumor cells, including LSCs. ${ }^{38}$ Constitutive activation of NF- $K \mathrm{~B}$ may provide an unique opportunity to preferentially target LSCs. Inhibition of NF- $k \mathrm{~B}$ can also induce intracellular ROS generation, leading to cell death. ${ }^{14}$ Consistent with previously observations that DS is an effective inhibitor of NF- $K B$, DS indeed downregulated p 65 and inhibited expression of the NF- $k \mathrm{~B}$ downstream genes in leukemia stemlike cells, whereas this event was markedly enhanced by co-administration of $\mathrm{Cu}$. Activation of the Nrf2 signaling pathway represents a major mechanism for cellular defense against oxidative stress. Its downstream targets are involved in detoxification of harmful chemicals and removal of reactive oxidants, consequently protecting cells from detrimental stresses. ${ }^{28}$ Therefore, Nrf2 might be a potential target for elimination of LSCs. In the present study, we observed that DS and $\mathrm{DS} / \mathrm{Cu}$ sharply reduced the protein level of Nrf2 both in vitro and in vivo in leukemia stem-like cells, as well as blocked the expression of Nrf2 target genes such as NQO1, GSR, and HO-1. Downregulation of Nrf2 was partially reversed by NAC, indicating that ROS increase might result in decrease of Nrf2, thereby impairing its ability to protect cells from ROS-mediated oxidative damage. Taken together, in addition to activation of the ROS-JNK signaling cascade, inactivation of NF-KB and Nrf2 might also contribute to antileukemia activity of DS/Cu toward leukemia stem-like cells. It is noteworthy that these pro-survival signaling pathways (e.g., $\mathrm{NF}-\kappa \mathrm{B}$ and Nrf2), as well as the stress-related ROS-JNK pathway, are determinants for tumor cell survival versus death in a variety of cancers. ${ }^{39-45}$ Thus, inactivation of NF-KB and Nrf2 signals and/or activation of the ROS-JNK signaling cascade might represent common mechanisms of action underlying the antitumor activity of DS/Cu in diverse cancers, including hematologic malignancies (e.g., myeloid and lymphoid leukemias) as we observed earlier. ${ }^{19,46}$

Collectively, the ability of DS in combination with $\mathrm{Cu}$ to eliminate leukemia stem-like cells in vitro and in vivo indicate that $\mathrm{DS} / \mathrm{Cu}$ might represent a promising therapeutic repurposed agent to preferentially target LSCs, while sparing normal hematopoietic progenitor cells. Mechanistically, the anti-leukemia property of DS/Cu might attribute to induction of apoptosis via ROS-mediated activation of the stress-related JNK pathway and inactivation of the NF- $\kappa$ B and Nrf2 pathways. Therefore, the combination of DS and $\mathrm{Cu}$ warrants further clinical investigation in treatment of refractory leukemia, particularly targeting LSCs to reduce recurrence of this disease.

\section{Materials and Methods}

Reagents. DS, copper chloride $\left(\mathrm{CuCl}_{2}\right)$, and NAC were purchased from SigmaAldrich (Dorset, UK) and dissolved in dimethyl sulfoxide or PBS, and freshly diluted to required concentrations in subsequent experiments with culture medium before use.

Primary patient samples. Mononuclear cells were isolated from peripheral blood samples of healthy donors for hematopoietic stem cell transplantation $(n=8)$ and bone marrow samples of newly diagnosed patients with AML $(n=17)$, which were obtained with the informed consent for research purposes only at Department of Hematology, Nanfang Hospital, Southern Medical University and Department of Hematology, First Affiliated Hospital of Xiamen University. This study is approved by the Ethics Review Board of Nanfang Hospital and First Affiliated Hospital of Xiamen University, and performed in accordance with the Declaration of Helsinki. Clinical characteristics are summarized in Table 1. Mononuclear cells were isolated by density gradient centrifugation using Lymphoprep (BD, Franklin Lakes, NJ, USA) and cultured in IMDM (HyClone, Thermo Scientific, Waltham, MA, USA) supplemented with $10 \%$ fetal bovine serum (FBS, Gibco, Life Technologies, Grand Island, NY, USA), $100 \mathrm{U} / \mathrm{ml}$ penicillin and $100 \mu \mathrm{g} / \mathrm{ml}$ streptomycin $(1 \times P / S)$ after enrichment with a CD34 selection MACS kit (Miltenyi Biotec, Bergisch Gladbach, Germany) according to the manufacturer's protocol.

Cell culture and sorting. KG1 $\alpha$ and Kasumi-1 cells were obtained from Tianjing Institute of Hematology, Chinese Academy of Medical Sciences and cultured in IMDM supplemented with $10 \%$ FBS and antibiotics $(1 \times P / S)$ in a $37^{\circ} \mathrm{C}$ incubator with $5 \% \mathrm{CO}_{2}$. The $\mathrm{CD} 34^{+} / \mathrm{CD} 38^{-}$population was obtained by staining with CD34-allophycocyanin (CD34-APC; Becton Dickinson Biosciences, Oxford, UK) and CD38-fluorescein isothiocyanate (CD38-FITC; Becton Dickinson Biosciences) and then subjected to sorting using FACS Aria II.

Cell viability assay. Cell viability was determined by MTT assay. $\mathrm{CD} 34^{+}$ $/ \mathrm{CD} 38^{-} \mathrm{KG} 1 \alpha$ cells and $\mathrm{CD} 34^{+} / \mathrm{CD} 38^{-}$Kasumi- 1 cells were inoculated in a 96-well plate at a density of $2 \times 10^{4} /$ well in $100 \mu$ l growth medium and then treated with designated doses of DS with or without $\mathrm{Cu}(1 \mu \mathrm{M})$ for $24 \mathrm{~h}$. Then, a final concentration of $5 \mathrm{mg} / \mathrm{ml}$ MTT in PBS was added to each well and incubated for $4 \mathrm{~h}$. Viable cells were detected by measuring absorbance at $490 \mathrm{~nm}$ using an Multisckan MCC340 microplate reader (Labsystem, Helsinki, Finland). All experiments were conducted in triplicate. $\mathrm{IC}_{50}$ value (half maximal inhibitory concentration) was calculated by GraphPad Prism 5.

Flow cytometric analysis of apoptosis. Annexin V-FITC/PI staining was performed according to the manufacturer's instruction to detect the apoptotic cells. In brief, $\mathrm{CD}_{3} 4^{+} / \mathrm{CD} 38^{-} \mathrm{KG} 1 \alpha$ cells, $\mathrm{CD} 34^{+} \mathrm{CD} 38^{-}$Kasumi- 1 cells, primary $\mathrm{CD} 34^{+}$ $\mathrm{AML}$ cells, and normal $\mathrm{CD} 34^{+}$hematopoietic cells were treated with escalating concentration of DS with or without $\mathrm{Cu}(1 \mu \mathrm{M})$ for $24 \mathrm{~h}$. Cells were harvested after washing twice with iced PBS and then stained with Annexin V-FITC/PI for 20 min at $4^{\circ} \mathrm{C}$ in the dark. The percentage of apoptotic cells was determined by FACS C6 (BD, Oxford, UK). At least 30000 gated events were acquired from each sample.

Measurement of intracellular ROS. Cells were exposed to DS alone or in combination with $\mathrm{Cu}(1 \mu \mathrm{M})$ for indicated time points $(6,12,18,24 \mathrm{~h})$, then 
supernatants were removed and cells were labeled with $2^{\prime}, 7^{\prime}$-dichlorofluorescindiacetate (DCFH-DA, Invitrogen, Paisley, UK) at $37^{\circ} \mathrm{C}$ for $30 \mathrm{~min}$. Cells were washed twice with PBS and maintained in $1 \mathrm{ml}$ serum-free medium. Cellular ROS level was analyzed using a FACS Calibur machine (Becton Dickinson, San Jose, CA, USA). Each sample was measured at least in triplicate.

Colony formation assay. The colony-forming capacity of $\mathrm{CD} 34^{+} / \mathrm{CD} 38^{-}$ $\mathrm{KG} 1 \alpha$ cells and $\mathrm{CD} 34^{+}$primary AML cells was measured using methylcellulose medium (Methocult H4434, Stem Cell Technologies, Vancouver, BC, Canada) according to the manufacturer's instructions. In brief, cells were cultured in six-well plates with Methocult $\mathrm{H} 4434$ at a density of 500 cells/well after treated with DS alone or in combination with $\mathrm{Cu}(1 \mu \mathrm{M})$ for $18 \mathrm{~h}$. After incubation at $37^{\circ} \mathrm{C}$ for $10-$ 14 days, CFU consisting of 40 or more cells were counted under microscope.

Western blot analysis. After cell lysis, $50 \mu \mathrm{g} / \mathrm{lane}$ of proteins from each sample was resolved in 10\% SDS-polyacrylamide gel electrophoresis and then transferred to PVDF membrane (Millipore, Billerica, MA, USA). After blocking with $5 \%$ non-fat milk in Tris-buffered saline-Tween 20 (TBS-T) for $2 \mathrm{~h}$, the membrane was incubated overnight at $4{ }^{\circ} \mathrm{C}$ with the primary antibody, followed by appropriate secondary HRP-conjugated antibody (1:10 000, Cell Signaling Technology, Herts, UK) in TBS-T for $2 \mathrm{~h}$ at room temperature. The proteins were visualized on X-ray film using an ECL Western blotting detection kit (Cell Signaling Technology). GAPDH and PCNA were probed as loading controls.

Quantitative real-time PCR (qPCR). Cells were lysed with Trizol reagent (Invitrogen, Carlsbad, CA, USA) and total RNA from each sample was extracted with chloroform and isopropyl alcohol. cDNA was synthesize using a reverse transcription reagent kit (TaKaRa, Dalian, China) according to the manufacturer's instructions. Quantitative real-time PCR was carried out by a SYBR Prime Script RTPCR kit (Takara) using the following primers (synthesized by Takara). The relative levels of mRNA expression were determined by the $2^{-\Delta \Delta C t}$ method.

NQ01: 5'-GTGGCAGTGGCTCCATGTACTC-3' (forward),

5'-GAGTGTGCCCAATGCTATATGTCAG-3' (reverse);

GSR: 5'-CCTGATCGCCACAGGTGGTA-3' (forward),

5'- CTGCCATCTCCACAGCAATGTAA-3' (reverse);

HO-1: 5' - TTGCCAGTGCCACCAAGTTC-3' (forward),

5'- TCAGCAGCTCCTGCAACTCC-3' (reverse);

GAPDH: 5'-TCTCTGCTCCTCCTGTTC-3' (forward),

$5^{\prime}$-CTCCGACCTTCADCTTCC-3' (reverse);

Animal study. NOD/SCID mice (6-8 weeks old, non-fertile, female, and 18-20 $\mathrm{g}$ each) were purchased from the Experimental Center of Southern Medical University and bred in a pathogen-free environment and supplied with sterile food and water. All animal study procedures were approved by Nanfang Hospital of Southern Medical University Animal Care and Use Committee. After receiving 1 Gy of sublethal irradiation, mice were intravenously injected with $2 \times 10^{6} \mathrm{CD} 34^{+}$ /CD38- KG1 $\alpha$ cells resuspended in $200 \mu \mathrm{l}$ PBS and then monitored weekly for signs of weight loss or lethargy, and leukocytes in peripheral blood. After percentage of $\mathrm{hCD}^{+} 5^{+}$in peripheral blood reached $1 \%$, mice were randomly assigned to three groups ( $n=8$ per group). DS/Cu treatment was given by gavage as follows: $3 \mathrm{mg} / 20 \mathrm{~g} / \mathrm{day}$ for DS per morning and $0.03 \mathrm{mg} / 20 \mathrm{~g} / \mathrm{day}$ for $\mathrm{Cu}$ per afternoon for 2 weeks. Ara-C treatment was given as follows for comparison: $40 \mathrm{mg} /$ $20 \mathrm{~g} /$ day for 2 days before killing. Mice of the control group received vehicle (i.e., PBS, $0.2 \mathrm{ml} / 20 \mathrm{~g} / \mathrm{d}$ for 2 weeks). Mice were killed after 2 weeks and invasion of leukemia cells was evaluated by H\&E staining for pathological changes and immunohistochemical staining for hCD45.

Immunohistochemical staining. Paraffin-embedded liver and spleen tissue from mice were sectioned and deparaffinized with xylene. Then slides were subjected to rehydration with different concentrations of alcohol. For antigen retrieval, slides were immersed in boiling citrate buffer for $30 \mathrm{~min}$ and then incubated with primary antibody against $h C D 45$ overnight at $4{ }^{\circ} \mathrm{C}$ after blocking with $3 \% \mathrm{BSA}$ solution at room temperature for $30 \mathrm{~min}$. After washing, HRP Polymer Conjugate Reagent (SuperPicture Polymer Detection kit) and DAB Chromogen were added. Mayer's Hematoxylin solution was used for counterstaining. Finally, slides were dehydrated, air-dried and mounted. For hematoxylin and eosin staining (H\&E stain) slides were immersed in a coplin jar containing Mayer's hematoxylin solution, washed with distilled water and then counterstained with eosin $Y$ solution.
Statistical analysis. All statistical analyses were performed using the SPSS 13.0 statistical software package. Comparisons between two groups were analyzed using the two-tailed Student's t-test. Comparisons among multiple groups were performed using the one-way ANOVA, followed by LSD test if the variance was homogenous, whereas if not, Dunnett's T3 was employed. ${ }^{*} P<0.05$ was considered as statistical significance.

\section{Conflict of Interest}

The authors declare no conflict of interest.

Acknowledgements. This work was financially supported by National Nature Science Foundation of China, PR China (No. 81070425, No. 81428003, No. 81570156) and the Guangdong Provincial Basic Research Program, PR China (No. 2015B020227003).

1. Bonnet $D$, Dick JE. Human acute myeloid leukemia is organized as a hierarchy that originates from a primitive hematopoietic cell. Nat Med 1997; 3: 730-737.

2. Hope KJ, Jin L, Dick JE. Acute myeloid leukemia originates from a hierarchy of leukemic stem cell classes that differ in self-renewal capacity. Nat Immunol 2004; 5 : 738-743.

3. Lapidot T, Grunberger T, Vormoor J, Estrov Z, Kollet O, Bunin N et al. Identification of human juvenile chronic myelogenous leukemia stem cells capable of initiating the disease in primary and secondary SCID mice. Blood 1996; 88: 2655-2664.

4. Reya T, Morrison SJ, Clarke MF, Weissman IL. Stem cells, cancer, and cancer stem cells. Nature 2001; 414: 105-111.

5. Li Y, Chen K, Zhou Y, Xiao Y, Deng M, Jiang Z et al. A new strategy to target acute myeloid leukemia stem and progenitor cells using chidamide, a histone deacetylase inhibitor. Curr Cancer Drug Targets 2015; 15: 493-503.

6. Lapidot T, Sirard C, Vormoor J, Murdoch B, Hoang T, Caceres-Cortes J et al. A cell initiating human acute myeloid leukaemia after transplantation into SCID mice. Nature 1994; 367 645-648.

7. Kikushige $\mathrm{Y}$, Shima T, Takayanagi SI, Urata S, Miyamoto T, Iwasaki H et al. TIM-3 is a promising target to selectively kill acute myeloid leukemia stem cells. Cell Stem Cell 2010; 7: 708-717.

8. Liu Y, Chen F, Wang S, Guo X, Shi P, Wang W et al. Low-dose triptolide in combination with idarubicin induces apoptosis in AML leukemic stem-like KG1a cell line by modulation of the intrinsic and extrinsic factors. Cell Death Dis 2013; 4: e948.

9. Johansson B. A review of the pharmacokinetics and pharmacodynamics of Disulfiram and its metabolite. Acta Psychiatr Scand Suppl 2008; 44: 15-26.

10. Suh JJ, Pettinati HM, Kampman KM, O'Brien CP. The status of disulfiram: a half of a century later. J Clin Psychopharmacol 2006; 26: 290-302.

11. Morrison BW, Doudican NA, Patel KR, Orlow SJ. Disulfiram induces copper-dependent stimulation of reactive oxygen species and activation of the extrinsic apoptotic pathway in melanoma. Melanoma Res 2010; 20: 11-20.

12. Brar SS, Grigg C, Wilson KS, Holder WD, Dreau D, Austin C et al. Disulfiram inhibits activating transcription factor/cyclic AMP-responsive element binding protein and human melanoma growth in a metal-dependent manner in vitro, in mice and in a patient with metastatic disease. Mol Cancer Ther 2004; 3: 1049-1060.

13. Cen D, Brayton D, Shahandeh B, Meyskens FL Jr, Farmer PJ. Disulfiram facilitates intracellular Cu uptake and induces apoptosis in human melanoma cells. J Med Chem 2005 47: 6914-6920.

14. Chen D, Cui QC, Yang H, Dou QP. Disulfiram a clinically used anti-alcoholism drug and copper-binding agent, induces apoptotic cell death in breast cancer cultures and xenografts via inhibition of the proteasome activity. Cancer Res 2006; 66: A92.

15. Yip NC, Fombon IS, Liu P, Brown S, Kannappan V, Armesilla AL et al. Disulfiram modulated ROS-MAPK and NFKB pathways and targeted breast cancer cells with cancer stem cell-like properties. Br J Cancer 2011; 104: 1564-1574.

16. Zhang H, Chen D, Ringler J, Chen W, Cui QC, Ethier SP et al. Disulfiram treatment facilitates phosphoinositide 3-kinase inhibition in human breast cancer cells in vitro and in vivo. Cancer Res 2010; 70: 3996-4004.

17. Guo X, Xu B, Pandey S, Goessl E, Brown J, Armesilla AL et al. Disulfiram/copper complex inhibiting NFKB activity and potentiating cytotoxic effect of gemcitabine on colon and breast cancer cell lines. Cancer Lett 2010; 290: 104-113.

18. Lin J, Haffner MC, Zhang $\mathrm{Y}$, Lee BH, Brennen WN, Britton $\mathrm{J}$ et al. Disulfiram is a DNA demethylating agent and inhibits prostate cancer cell growth. Prostate 2011; 71: 333-343.

19. Zha J, Chen F, Dong H, Shi P, Yao Y, Zhang Y et al. Disulfiram targeting lymphoid malignant cell lines via ROS-JNK activation as well as Nrf2 and NF-kB pathway inhibition. J Transl Med 2014; $12: 1-9$.

20. Xu B, Shi P, Fombon IS, Zhang Y, Huang F, Wang W et al. Disulfiram/copper complex activated $\mathrm{JNK} / \mathrm{c}$-jun pathway and sensitized cytotoxicity of doxorubicin in doxorubicin resistant leukemia HL60 cells. Blood Cells Mol Dis 2011; 47: 264-269. 
21. Liou GY, Storz P. Reactive oxygen species in cancer. Free Radic Res 2010; 44: 479-496.

22. ErebiáTawari $P$, WaiáTsang $C$. The cytotoxic mechanisms of disulfiram and copper (ii) in cancer cells. Toxicol Res 2015; 4: 1439-1442.

23. Davis RJ. Signal transduction by the JNK group of MAP kinases. Cell 2000; 103: 239-252.

24. Tournier C, Hess P, Yang DD, Xu J, Turner TK, Nimnual A et al. Requirement of JNK for stressinduced activation of the cytochrome c-mediated death pathway. Science 2000; 288: 870-874.

25. Dhanasekaran DN, Reddy EP. JNK signaling in apoptosis. Oncogene 2008; 27: 6245-6251.

26. Verma G, Datta M. The critical role of JNK in the ER-mitochondrial crosstalk during apoptotic cell death. J Cell Physiol 2012; 227: 1791-1795.

27. Guzman ML, Neering SJ, Upchurch D, Grimes B, Howard DS, Rizzieri DA et al. Nuclear factor- $\mathrm{KB}$ is constitutively activated in primitive human acute myelogenous leukemia cells. Blood 2001; 98: 2301-2307.

28. Baird L, Dinkova-Kostova AT. The cytoprotective role of the Keap1-Nrf2 pathway. Arch Toxicol 2011; 85: 241-272.

29. Sporn MB, Liby KT. NRF2 and cancer: the good, the bad and the importance of context. Nat Rev Cancer 2012; 12: 564-571.

30. Taguchi K, Motohashi H, Yamamoto M. Molecular mechanisms of the Keap1-Nrf2 pathway in stress response and cancer evolution. Genes Cell 2011; 16: 123-140.

31. Yamadori T, Ishii $\mathrm{Y}$, Homma S, Morishima $\mathrm{Y}$, Kurishima $\mathrm{K}$, Itoh $\mathrm{K}$ et al. Molecular mechanisms for the regulation of Nrf2-mediated cell proliferation in non-small-cell lung cancers. Oncogene 2012; 31: 4768-4777.

32. Furley AJ, Reeves BR, Mizutani S, Altass LJ, Watt SM, Jacob MC et al. Divergent molecular phenotypes of KG1 and KG1a myeloid cell lines. Blood 1986; 68: 1101-1107.

33. Gupte A, Mumper RJ. Elevated copper and oxidative stress in cancer cells as a target for cancer treatment. Cancer Treat Rev 2009; 35: 32-46.

34. Cvek B, Dvorak $Z$. The value of proteasome inhibition in cancer: Can the old drug, disulfiram have a bright new future as a novel proteasome inhibitor? Drug Discov Today 2008; 13: 716-722.

35. Conticello C, Martinetti D, Adamo L, Buccheri S, Giuffrida R, Parrinello N et al. Disulfiram, an old drug with new potential therapeutic uses for human hematological malignancies. Int J Cancer 2012; 131: 2197-2203.

36. Larson RA. Is secondary leukemia an independent poor prognostic factor in acute myeloid leukemia? Best Pract Res Clin Haematol 2007; 20: 29-37.

37. Cao XH, Wang AH, Wang CL, Mao DZ, Lu MF, Cui YQ et al. Surfactin induces apoptosis in human breast cancer MCF-7 cells through a ROS/JNK-mediated mitochondrial/caspase pathway. Chem Biol Interact 2010; 183: 357-362.
38. Rayet B, Gélinas C. Aberrant rel/nfkb genes and activity in human cancer. Oncogene 1999; 18: $6938-6947$

39. Kaminskyy VO, Zhivotovsky B. Free radicals in cross talk between autophagy and apoptosis. Antioxid Redox Signal 2014; 21: 86-102.

40. Cartwright T, Perkins ND, Wilson CL. NFKB1: a suppressor of inflammation, ageing and cancer. FebS J 2016; 283: 1812.

41. Durand N, Storz P. Targeting reactive oxygen species in development and progression of pancreatic cancer. Expert Rev Anticancer Ther 2016; 17: 19.

42. Krajka-Kuźniak V, Paluszczak J, Baer-Dubowska W. The Nrf2-ARE signaling pathway: an update on its regulation and possible role in cancer prevention and treatment. Pharmacol Rep 2016; 69: 393-402.

43. Mitchell S, Vargas J, Hoffmann A. Signaling via the NF kappa B system. Wiley Interdiscip Rev Syst Biol Med 2016; 8: 227-241.

44. Shaukat Z, Liu D, Hussain R, Khan M, Gregory SL. The role of JNK signalling in responses to oxidative DNA damage. Current Drug Targets 2016; 17: 154-163.

45. Kang KA, Hyun JW. Oxidative stress, Nrf2, and epigenetic modification contribute to anticancer drug resistance. Toxicol Res 2017; 33: 1-5

46. Deng M, Jiang Z, Li Y, Zhou Y, Li J, Wang X et al. Effective elimination of adult B-lineage acute lymphoblastic leukemia by disulfiram/copper complex in vitro and in vivo in patientderived xenograft models. Oncotarget 2016; 7: 82200-82212.

Cell Death and Disease is an open-access journal published by Nature Publishing Group. This work is licensed under a Creative Commons Attribution 4.0 International License. The images or other third party material in this article are included in the article's Creative Commons license, unless indicated otherwise in the credit line; if the material is not included under the Creative Commons license, users will need to obtain permission from the license holder to reproduce the material. To view a copy of this license, visit http://creativecommons.org/licenses/by/4.0/

(C) The Author(s) 2017

Supplementary Information accompanies this paper on Cell Death and Disease website (http://www.nature.com/cddis) 